\section{That is disgusting! Should I trust you?: The role of mindsets in brand trust after a negative incident}

\author{
Rogelio Puente-Díaz ${ }^{1}$ \\ ${ }^{1}$ Anáhuac University, Department of Business and Economics, Mexico
}

Judith Cavazos-Arroyo ${ }^{2}$

${ }^{2}$ Popular Autonomous University of Puebla State (UPAEP), Graduate Interdisciplinary Center, Puebla, Mexico
Received on

03/27/2018

Approved on

$11 / 30 / 2018$

Responsible editor:

Profa. Dra Susana Costa

Evaluation process:

Double Blind Review

\begin{abstract}
Purpose - The purpose of this investigation was to examine the influence of mindsets on consumers' reactions to a negative event involving a corporate brand.
\end{abstract}

Design/methodology/approach - We conducted two studies, one qualitative and one quantitative. In study 1, participants were shown a picture of the incident with a caption and personal interviews were conducted with consumers of the category involved in the event, i.e. green chilies. In study 2, participants were shown the same picture as in study 1 and completed a set of questionnaires assessing mindsets, brand trust, and purchase intention.

Findings - Study 1 showed the presence of a theme involving the stability versus malleability of brands, used to explain the decision to either trust and purchase the brand again or not. Study 2 showed a positive relationship between a growth mindset and brand trust. Similarly, brand trust was positively related to purchase intention. The latent class model showed that the two classes with higher levels of a growth mindset were more likely to trust the brand and purchase it after the negative event.

Originality/value - To our knowledge, only one investigation has examined the role of mindsets in consumers' reactions after a negative incident involving a corporate brand. Hence, this investigation tried to answer a recent call from several consumer behavior scholars for more research on mindsets.

Keywords - Mindsets, brand trust, corporate brands, implicit theories

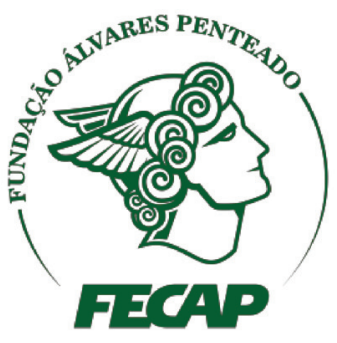

Review of Business Management 


\section{Introduction}

On July 22nd of 2016, La Costeña - a Mexican corporate brand known, among other aspects, for its canned green chilies - woke up to the news that a picture (see Appendix A) showing two of its factory employees, one of them halfnaked and apparently urinating on the green chilies, was uploaded to social media and had been viralized. The CEO of La Costeña stated that the picture was real, but that it was impossible that one of the employees had urinated on the green chilies, and that more than 10,000 cans had been inspected without finding any trace of urine. As one would imagine, the CEO was concerned about losing consumers' trust in the hygiene and safety of La Costeña products, considering the amount of attention given to the incident on the internet (see Figure 1). Theoretical and empirical work on brand trust in the food industry suggests that trust plays a key role (Lassoued \& Hobbs, 2015). Given the importance of understanding brand trust after negative events or product crises, our investigation tries to shed light on how consumers' reactions might be explained by a variable known as mindsets or implicit theories.

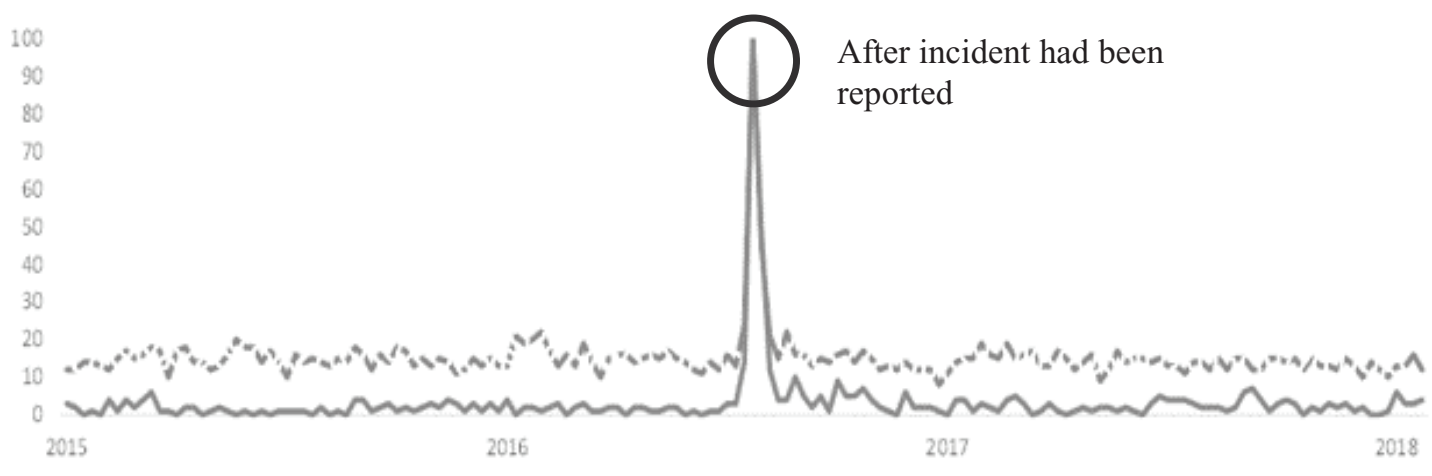

.....เล Costeña -Green Chilies La Costeña

Figure 1. Amount of searches for the key words "La Costeña" and "green chilies La Costeña” in Google trends over three years (2015-2018)

In hypercompetitive environments, companies recognize the value and importance of product and corporate brands (Brexendorf \& Keller, 2017; Tybout \& Calkins, 2005). The importance of brands comes primarily from the relationships consumers develop with them (Alvarez \& Fournier, 2016). Like in any relationship between two parties, one side could "make a mistake" or "be involved" in a negative event. These negative events could challenge and question the trust relationship formed between brands and consumers. Traditionally, business researchers have paid closer attention to how companies or brands handle the trust repairing efforts (Yin, Yu, \& Poon, 2016) without paying as much attention to the characteristics of consumers. Yet, this general trend has started to shift. Specifically, recent developments in consumer behavior research have proposed that implicit theories or mindsets, and whether individuals believe personal characteristics are stable or malleable, might have important implications for understanding how consumers react to negative events involving product and corporate brands (Murphy \& Dweck, 2016). These recent propositions also acknowledge that 
more empirical research is needed (Murphy \& Dweck, 2016) based on real companies and business scenarios (Yin et al., 2016). Similarly, a recent literature review on product-harm crises makes a call for more research in different countries (Cleeren, Dekimpe, \& van Heerde, 2017). Hence, the purpose of our investigation is to examine how consumers react to a negative event in which a strong, Mexican corporate brand from the food industry is involved, and assess if these reactions could be explained by individual differences in mindsets. In order to achieve our research goals, we first explain the importance of brand trust and some of its consequences: purchase intention and brand loyalty. We then explore the nature of implicit theories or mindsets, followed by an explanation of how they have been used in consumer research. Last, we propose how our current investigation might enhance our understanding of consumers' reactions after a negative event and develop research hypotheses.

\section{I.2 Brand trust and its positive consequences}

The concept of brand trust has important implications for general marketing and it is especially relevant for the food industry (Lassoued \& Hobbs, 2015). In the buyer-seller relationship, consumers need to have confidence that corporate brands can assure the quality, safety, and hygiene of their food products. Hence, consumers need to trust corporate and product brands in order for a relationship to be established (Morgan \& Hunt, 1994). Failing to develop trust would make the relationship between consumers and food brands difficult, if not impossible, to establish. Hence, it is not surprising to observe that brand trust has been widely examined in general marketing and the food industry.

One of the first empirical examinations, using over 100 brands from a wide range of categories, found that brand trust was a significant direct predictor of behavioral and attitudinal brand loyalty and that it indirectly influenced important marketing indicators such as market share and relative price as well (Chaudhuri \& Holbrook, 2001). Recent investigations focusing on different categories or industries, such as store brands and food, have also found support for the role of brand trust (Calvo-Porral \& LevyMangin, 2016; Lassoued \& Hobbs, 2015). Regarding specific empirical studies examining trust in the food industry, one found that brand trust had a positive relationship with trust in the food industry, which then influenced consumers' confidence. Consumers' confidence was then positively related to brand loyalty (Lassoued \& Hobbs, 2015). These authors suggested that trust is particularly relevant in the food industry given that consumers might face uncertainty regarding how important actors (government regulators, companies, and brands) in the industry handle safety and hygiene issues. Similar results were obtained when examining the role of brand trust in the restaurant industry (Han, Nguyen, \& Lee, 2015).

In the theoretical and empirical work just reviewed, general, context-independent trust was examined. While this research is valuable, we need to include the examination of trust after it has been questioned or challenged. One suggestion indicates that trust might play a more important role under conditions of uncertainty (Doney \& Cannon, 1997). Hence, we need to include the examination of trust after negative events or product crises. For example, a longitudinal study on consumer confidence in the safety of food showed that trust in corporate brands was one of the strongest predictors of consumer confidence (de Jonge, van Ttrijp, Renes, \& Frewer, 2010). In addition, this longitudinal study also established that media coverage of negative food incidents influenced consumers' memory of food incidents and confidence, suggesting that food safety and hygiene were relevant issues for consumers and that media coverage, to some extent, helped shape their views.

Regarding a specific product and brand failure closer to the one we seek to explore, researchers examined the role of trust in a 
well-known yogurt brand after it was involved in a negative incident (Dawar \& Pillutla, 2000; Yannopoulou, Koronis, \& Elliot, 2011). Specifically, the researchers examined if brand trust after a product failure (traces of mold) in the yogurt category was influenced by whether consumers personally experienced the product flaw or they read or heard about it through mass media outlets (Yannopoulou et al., 2011). The results showed that product failure had a stronger negative influence on brand trust when consumers read or heard about it on the news than when they had a personal experience with the product. Consumers that directly experienced the product flaw tended to forgive the brand and used words reflecting an incident that is malleable in nature (it was just a one-off, an unfortunate accident), suggesting that how malleable or fixed consumers believe brand performance to be has important implications for maintaining brand trust after a product failure. These results have important implications for our investigation for three reasons: 1) the research examined brand trust after a brand experienced a credibility crisis regarding the safety and hygiene of its products; 2) it assessed how mass media influenced brand trust, consistent with how the brand scandal of La Costeńa unfolded; 3) even though it did not specifically examine mindsets, the qualitative results reported in the article were consistent with the idea that words reflecting a malleable or fixed belief in things do play a role in consumers' discourse regarding brand trust.

Having established the role of brand trust in the food industry, we now turn our attention to explaining why mindsets or implicit theories might play an important role in consumers' reactions. We first review the general theoretical propositions of implicit theories, followed by their applications to a wide variety of consumer-related phenomena.

\section{3 Implicit theories and consumer trust}

At the core of implicit theories is the belief that entities (humans, brands, groups, companies) are fixed with little room for improvement, i.e a fixed mindset, or the belief that entities change, improve, and grow, i.e. a growth mindset (Dweck, 2000; Plaks, 2017). This simple, yet robust theoretical proposition has caught the attention of researchers in different areas, including organizational (Murphy \& Dweck, 2010) and consumer behavior (Wheeler \& Omair, 2016), with important implications for understanding brand trust after a brand has been involved in a negative incident. Specifically, consumers might believe that brands and companies show consistency and stability across time and/or that brands and companies show change and growth. There is evidence indicating that consumers can perceive brands as more stable or malleable (Aaker, Fournier, \& Brasel, 2004). The belief that brands and companies are stable or malleable might influence a wide variety of marketing outcomes, including consumers' reactions after brands are involved in a negative event (Murphy \& Dweck, 2016; Yin et al., 2016), which is the focus of our investigation.

In order to show how mindsets influence consumers' trust, we need to explain how consumers interact with brands and how mindsets influence consumers' cognition. Regarding the former, consumers develop relationships with brands (Alvarez \& Fournier, 2016). During the process of relationship initiation and development, it is common for brands to make "mistakes" or "are involved" in negative events. For example, a well-known brand of yogurt in Greece and the rest of Europe had to recall thousands of products after consumers complained about finding traces of mold. Similarly, a fast-food brand in the USA Chipotle - had to close because, in one of several incidents, more than 100 customers became sick with a norovirus after eating at the restaurant. What these examples have in common is that companies and brands seek to explain to the public what happened and make efforts to assess consumers' reactions in terms of brand trust and purchase intention. These efforts make intuitive sense given that most consumers would not want 
to buy a yogurt, for example, that could contain significant traces of bacteria. Issues of trust in the safety and hygiene of products appear to be particularly relevant for the food industry.

Regarding mindsets, the key assumption is that they - whether one believes in the malleability or stability of things - influence cognition by directing one's attention, making some information more memorable, and attributing successful and flawed performances to stable or malleable factors (Plaks, 2017). Hence, mindsets can generate a bias in which individuals tend to pay more attention and interpret information in a way that is consistent with their mindset, influencing judgments of product failures. Individuals holding high levels of a fixed (growth) mindset or with a profile characterized by a fixed (growth) mindset would be more (less) likely to perceive a performance flaw as a stable, negative reflection of brand performance. Hence, consumers with such characteristics would be less likely to trust a brand or express interest in purchasing it after a flaw in performance. Given that the potential consequences of negative events involving brands have usually been examined by analyzing the behavior of companies and brands (Yin et al., 2016), we propose that mindsets could explain whether consumers are able to trust a brand after a negative event.

When reviewing the empirical literature on mindsets and product crises, only a few investigations were found (e.g., Yin et al., 2016). Specifically, one of these investigations examined the influence of mindsets on consumers' attributions and brand evaluations of fictitious brands involved in fictitious negative events and whether consumers' reactions were moderated by corporate brand image and recovery strategy (support versus stonewalling). Results from two experiments, for the most part, supported the idea that brand evaluations were more positive among participants who endorsed a growth mindset. Yet, the influence of a growth mindset was qualified by recovery strategy and by the strength of the corporate brand image involved in the fictitious incident.
Even though the abovementioned investigation made a significant contribution to our understanding of mindsets and brand evaluations after negative events, it had at least three limitations. First, the researchers dichotomized the scores from the implicit theories scale to form two groups, growth and fixed mindsets, to assess how group membership affected brand evaluations. This analytical strategy has serious shortcomings given that there are better techniques available such as latent class analysis to form groups (Bergman \& Andersson, 2010). Second, the researchers used fictitious brands and negative incidents, limiting the external validity of the findings. Brand scandals become scandals because consumers care about them and pay attention to them. Using real product failures of existing brands might help us get a better understanding of how mindsets influence consumers' reactions. Third, the abovementioned investigation focused on brand evaluations without assessing brand trust, which represents an important limitation given that brand trust is likely to play a significant role after brands are involved in negative events. In order to address these shortcomings, we use, in one of our two analyses, latent class analysis to form groups. In addition, we use a real company and business scenario to examine consumers' reactions after a negative event, and we also explore the role of brand trust.

Regarding the conceptualization of mindsets and our research hypotheses, we suggest that mindsets could be conceptualized in two different ways: as latent variables and as latent classes. Both conceptualizations can be estimated to test complementary hypotheses. Hence, we propose the following. Under the latent variable conceptualization, we expect a positive relationship between a growth mindset and brand trust (hypothesis one). Conversely, we expect a negative relationship between a fixed mindset and brand trust (hypothesis two). Under the latent class conceptualization, we suggest that a class characterized as having a high growth mindset 
and a low fixed mindset would show higher levels of brand trust than a class characterized by either low levels of a growth mindset or high levels of a fixed mindset (hypothesis three). In addition, we expect brand trust to have a positive relationship with brand purchase intention under the latent variable approach (hypothesis four) (Xie, Batra, \& Peng, 2015), indicating a significant indirect effect of a growth mindset on purchase intention. Last, we also suggest that a latent class characterized by a high growth mindset and a low fixed mindset would show higher levels of brand purchase intention than a class characterized by either low levels of a growth mindset or high levels of a fixed mindset (hypothesis five).

In sum, the purpose of our investigation is twofold. First, in study 1 we conduct a qualitative study using personal interviews to examine if the key dimension of implicit theories, stability versus malleability, is part of the natural discourse consumers use to explain their reactions to a negative event involving a Mexican corporate brand. Specifically, we seek in the natural discourse of consumers any mentions of two core components of mindsets: 1) a belief that behavior is a reflection of an unchangeable personality trait of a brand (a fixed belief) versus a belief that the context influences the behavior of brands (a growth belief); 2) a belief that performance is consistent across time and situations (a fixed mindset) versus a belief that performance can vary across time and situations (a growth mindset) (Puzakova, Kwak, \& Rocereto, 2013). Second, in study 2 we examine how consumers respond to the same negative event, as in study 1 , and assess whether individual differences in mindsets are able to explain consumers' reactions under two different conceptualizations of mindsets: latent variable and latent class.

\section{Method}

\section{I Participants of study 1}

The participants were fourteen middleaged consumers (ages ranged from 30 to 50 years old) of green chilies, twelve females and two males, who worked as administrators in two private universities in Mexico. Hence, we used a convenience sample with relevance given they were all consumers of the category under investigation. The participants did not receive any financial compensation and were debriefed after their participation.

\subsection{Procedure of study 1}

Semi-structured interviews were conducted. The participants were presented with a picture and a brief description of the incident involving a Mexican corporate brand (see Appendix A). The photograph was really explicit (it was the picture shown in the Mexican newspapers), showing one of the employees halfnaked (the bottom part) with the machine and the green chilies really close to his body. The caption of the picture said the following (mainly taken from newspapers and public sources):

"The picture above shows two employees from the company La Costeña taking a selfie inside the company's plant that was uploaded to social media. The picture apparently shows one of the employees urinating on the chilies that are going to be canned and sold to the general public. The company's CEO made a public statement acknowledging that the picture was real but stating that it was a lie that the employee had actually urinated on any of the chilies and that more than 12,000 cans had been examined without finding any traces of urine."

After reading this description, the participants answered mostly open-ended questions, with a few exceptions, regarding their overall impressions of the negative event, their trust in the brand, and their intentions to buy the brand again. The interviews lasted between 10 and 15 minutes. All the interviews were transcribed and their content analyzed.

\section{Results}

We transcribed all the interviews in order to conduct a thematic analysis (Braun \& Clarke, 
2006; Onwuegbuzie \& Teddlie, 2003). As part of our exploration of major themes, we examined if the stability versus malleability component played any role in consumers' reactions to the event. Our main goal was to provide a descriptive understanding of the role that mindsets played in consumers' reactions to a negative event. In order for a major theme to be identified, it had to be mentioned by more than one participant. Two independent judges, blind to the hypotheses, helped with the coding process.

The result showed the presence of five major themes: emotional reactions, brand history/ heritage, doubt/disbelief, brand attributes, and stability versus malleability. This was consistent with the findings from a recent literature review on product-harm crises, suggesting consumers' reactions are multi-dimensional (Cleeren et al., 2017). Even though the discussion of the five major themes was relevant, we focused more attention on the stability versus malleability theme, given that it was the main reason for conducting a qualitative, exploratory study.

The emotional reaction theme captured the affective reactions evoked by the event. Consumers experienced surprise, disgust, and embarrassment, among other emotions. Given the explicit nature of the incident and the fact that the product was something edible, it was not surprising to find that the event evoked strong negative, affective reactions, as illustrated in the following quote:

\section{It is disgusting and shows a lack of values from the employees}

(Interviewee 1)

The corporate brand involved in the negative event had a long tradition in the Mexican market. Some consumers emphasized the tradition and heritage of the corporate brand. Hence, brand history/heritage represented another major theme that was used, mainly, as a way to justify the decision to trust the brand.
For example, when asked if they would trust the brand, some consumers replied:

Yes, because they have been in the market for a long time, they have tradition and the capacity to solve this problem

(Interviewee 1)

Our third theme, doubt/disbelief, represented probably the most difficult dilemma for consumers, in which they were faced with the decision to show brand trust or not. Hence, this theme was multidimensional. Some consumers talked about doubt, referring to their willingness to consider the brand again. For example, some consumers reported:

Trust is really complicated. They did check the cans and I believe them but I would not trust them again. Something similar happened to Gerber

(Interviewee 2)

Another set of consumers mentioned doubt, but in a different context. Given the power of social media to report facts but also fabricate events, some consumers expressed doubt about how the whole event had actually unfolded. For example:

\section{I am not even sure they actually urinated}

(Interviewee 5)

Brand attributes was another major theme found in the consumers' discourse. This theme was consistent with the idea that brands are complex stimuli with multiple attributes and that brand evaluations could be holistic (Acker, 1991). For example, when asked about their willingness to buy the product again, some consumers reported:

The products are good and they have worked hard to build a strong brand (Interviewee 11)

Yet, this theme was also used to justify unwillingness to buy the brand again as illustrated by the following quote: 
The brand is not that good to begin with (Interviewee 12)

Our fifth theme, stability versus malleability, was the most important for our investigation. As explained earlier, we were seeking for any mentions reflecting beliefs about how one incident might reflect an enduring and unchangeable characteristic of a brand versus beliefs about the role of contextual factors, in addition to any mentions reflecting the stability (instability) and consistency (inconsistency) of brand performance across time and situations. The transcripts showed that consumers naturally expressed their beliefs about the stability versus malleability of brands and companies. Sometimes, this theme was used to assure willingness to trust the brand, whereas at other times it was used to do the opposite, suggesting that mindsets played an important role. For example, some consumers reported a belief in the malleability of things:

It happens to all companies, all people. Employees let the company down and all that the company has to do is fix it

(Interviewee 1)

A mistake does not make you a bad company, all companies make mistakes

(Interviewee 11)

By talking about the universal nature of mistakes, the need to fix problems, and the idea that a single episode does not define a company, the participants appeared to hold a malleable belief regarding corporate brand performance. Companies often face challenges and their performance can improve, reflecting a growth mindset. Further evidence came from other consumers, as shown in the following quotes:

After the incident, the company probably reinforced its quality control measures

(Interviewee 5)
It was a big attention lapse, a distraction on the part of the supervisors

(Interviewee 4)

Companies need to continue improving, evolving

(Interviewee 9)

The three quotes above were also consistent with a malleable belief about corporate brand performance. The first quote reflected the belief that the company took actions to prevent future incidents, implying a learning process. The second quote also implied a momentary instance of bad performance. In the last, referring to the need for continuous improvement, the consumer was implying that change and growth were possible.

Conversely, other consumers expressed a belief about the stability of things:

It gives me confidence they checked the cans but it will leave a "mark" on the trust in the company, I would not buy from it again, but you never know

(Interviewee 2)

I would not buy from it again. I actually used to buy its products but stopped after this incident. A mistake like that tells you that there are probably more behind closed doors (Interviewee 14)

They were caught doing that, right? I would not trust them again

(Interviewee 9)

The first quote was consistent with the idea that a single mistake might be a reflection of corporate brand performance that is consistent across time and situations. Even though the participant acknowledged that checking cans should give consumers confidence, she was not able to trust the brand again, implying indirectly that mistakes could occur again. Similarly, the other quotes reflected the belief that mistakes could point to more than just a single incident. 
They might reflect a core characteristic of the corporate brand. Hence, all these quotes appeared to suggest a fixed view of corporate brand performance, reflecting a fixed mindset.

\section{Brief discussion of study 1}

For the most part, the results showed that the stability versus malleability component emerged as part of the consumers' discourse to justify their decision to either trust or buy the brand in the future, lending support to the role of mindsets. These results were consistent with the findings from two previous investigations, one quantitative (Yin et al., 2016) and one qualitative (Yannopoulou et al., 2011). However, there are two caveats. First, in their discourse the participants appeared to either hold a malleable or fixed belief about the corporate brand but not both. This is important because implicit theories assume that individuals could hold both mindsets. Second, it is important to mention that other dimensions were also used to justify the decision to trust or buy the brand in the future, lending support to the multi-dimensional nature of brands.

While we acknowledge the importance of the qualitative findings, we also recognize their limitations. Mindsets represent beliefs about the stability and malleability of the world, including brands. Consumers are likely to show individual differences in their endorsement of a growth or a fixed belief. These individual differences could be conceptualized as latent variables or as latent classes. Hence, we conducted study two to examine the role of the two conceptualizations of mindsets in brand trust and purchase intention. Our goal was to capitalize on the strength and robustness of sequential mixed methods research, in which a quantitative approach sheds additional light and provides somewhat confirmatory evidence of the role of mindsets in consumers' reactions (Johnson \& Onwuegbuzie, 2004). Given that our main objective was to examine the role of a growth and a fixed mindset, we only assessed these two constructs, neglecting to assess other potential predictors of consumers' reactions uncovered in our qualitative study. Given the current trend of using more domain-specific assessments of mindsets (see the work on creative mindsets by, for example, Karwowski, 2014), we adapted the original mindset questionnaire (Levy, Stroessner, \& Dweck, 1998) to the domain of brands and companies.

\section{Method}

\section{I Participants of study 2}

The participants were 422 (59\% females and $41 \%$ males; ages 18 to $50, M=21.96$ years old, and SD $=3.42$ ) college and master business students from Mexico who identified themselves as consumers of the category under investigation, i.e. green chilies. Hence, we used a convenience sample. Questionnaires were administered individually with up to two or three participants completing their questionnaires in each session. Participation lasted between 8 and 10 minutes.

\section{$5 \cdot 2$ Measures of study 2}

Based on previously developed questionnaires to assess mindsets (Levy, Stroessner, \& Dweck, 1998), we developed six items measuring growth and fixed mindsets regarding brands and companies, using a scale from 1 (completely false) to 7 (completely true). The development of domain-specific measures of the malleability-stability of different variables is consistent with recent trends in mindset research (Plaks, 2017). Specifically, measures have been developed to assess the malleability and stability of empathy (Schuman, Zaki, \& Dweck, 2015), happiness (Tullet \& Plaks, 2016), and age groups (Neel \& Lassetter, 2015).

In line with the research efforts just described, when developing all items, we focused on the idea that the fixed items should reflect 
stability whereas the growth items should reflect malleability. Consistent with research in other domains (Karwowski, 2014) and with the original conceptualization of mindsets (Dweck, 2000), we treated growth and fixed mindsets as relatively independent, yet correlated dimensions.

We used Mplus 7.11 to test our latent variable model. We report a combination of absolute and incremental fit indices: $\chi^{2}$, Root Mean Square Error of Approximation (RMSEA), Incremental Fit Index (IFI), and Tucker Lewis Index (TLI). We used the cutoff scores of RMSEA $<.08$ and CFI and TLI > .90 as the minimum acceptable levels of model fit (West, Taylor, \& Wu, 2012).

Given that our measure was new, we conducted a confirmatory factor analysis of the questionnaire. The results showed an acceptable model fit: $\chi^{2}=20.44, \mathrm{p}<.001(\mathrm{df}=7)$, RMSEA $=.07, \mathrm{p}$ of close fit RMSEA $=.17, \mathrm{CFI}=.97$, and $\mathrm{TLI}=$.93. Examination of the standardized factor loadings revealed that they were all significant and in the expected direction (ranging from .32 to .78, see Table 1). Yet, one of the loadings, .32, was relatively low, indicating that this particular item might not represent the latent construct of fixed mindset as well as the other items. The latent correlation between the growth and fixed mindset was .51, lending evidence to the importance of conceptualizing both mindsets as related but relatively independent. Even though the correlation between both latent constructs was below the threshold of .85 posited by some scholars (Brown, 2006) as evidence for discriminant validity, we conducted an additional analysis testing a one-factor model. The results showed a poor model fit: $\chi^{2}=59.28, \mathrm{p}<.001$ $(\mathrm{df}=8)$, RMSEA $=.12$, $\mathrm{p}$ of close fit RMSEA $<.001$, CFI $=.87$, and TLI $=.76$. Based on the results from the one-factor model, we concluded that the new scale was conceptualized better as a two-factor model with correlated factors. Given that our research approach was somewhat exploratory and that the assessment of the psychometric properties of a measure is an ongoing, never-ending process (Kline, 1998), we continued testing our complete measurement model, acknowledging some of the limitations of our new measure.

Table 1.

\section{Standardized loadings for the two-factor solution}

\begin{tabular}{lcc}
\hline & Fixed & Growth \\
\hline Companies that start being good continue being good & 0.32 \\
Companies learn from their mistakes & 0.37 \\
Companies constantly evolve & 0.78 \\
Companies are always looking for ways to improve & 0.71 \\
Companies experience few changes across time & 0.40 \\
A company that is the leader continues to be the leader across time & 0.62 \\
\hline
\end{tabular}

Brand Trust. To measure brand trust, we used four items specific to the product-crisis scenario. The four items assessed were: trust in the hygiene of food, trust in the quality of food, trust in the quality control procedures employed by the company, and trust in the company CEO's statement about the measures taken after the incident.

Purchase intention. To measure purchase intention, we used two items. The first item assessed purchase intention for the product involved in the crisis, i.e. green chilies, and the 
second item assessed purchase intention for other products. The exact wording was: "How willing would you be to buy La Costeńa chilies?" and "How willing would you be to buy other La Costeńa products?”

\section{$5 \cdot 3$ Procedure of study 2}

As with any brand-related negative event, consumers vary in their levels of awareness ${ }^{1}$. To control for this and in order to rely less on memory, the participants were again presented with the same picture and description of what actually happened, as in study 1 . After reading this description, the participants answered the questions about brand trust and purchase intention and the questions assessing mindsets. The participants were then debriefed and thanked for their participation.

\section{Results of the latent variable model}

The results for the measurement model of the latent variables growth and fixed mindsets, trust, and purchase intention showed an acceptable model fit: $\chi^{2}=145.32, \mathrm{p}<.001(\mathrm{df}=43)$, RMSEA $=.07, \mathrm{p}$ of close fit RMSEA $=.001, \mathrm{CFI}=.95$, and $\mathrm{TLI}=.92$. Examination of the standardized factor loadings revealed that they were all significant and in the expected direction (ranging from .32 to .90). The latent correlations showed acceptable levels of discriminant validity (Brown, 2006) ranging from .01 to .83 (see Table 2 for descriptive statistics, latent correlations, and $H$ coefficients). Given that the fit of the measurement model was acceptable, we proceeded to testing our structural model.

Table 2

Descriptive statistics, latent correlations, and $\mathrm{H}$ coefficients for measurement model

\begin{tabular}{lcccc}
\hline & Growth & Fixed & Trust & Intention \\
\hline Growth & 0.66 & & & \\
Fixed & $0.42^{*}$ & 0.80 & & \\
Trust & $0.25^{*}$ & 0.06 & 0.89 & \\
Intention & $0.29^{*}$ & 0.01 & $.83^{*}$ & 0.89 \\
Mean & 5.49 & 3.80 & 4.42 & 4.90 \\
Range & $1.67-7.00$ & $1.00-7.00$ & $0.00-9.75$ & $0.00-10.00$ \\
SD & 1.06 & 1.24 & 2.46 & 2.95 \\
\hline
\end{tabular}

* Significant at the .05 level

$H$ coefficients on the diagonal

The results showed an acceptable model fit: $\chi^{2}=165.46, \mathrm{p}<.001(\mathrm{df}=50)$, RMSEA $=$ $.07, \mathrm{p}$ of close fit RMSEA $=.001, \mathrm{CFI}=.94$, and TLI $=.92$. Examination of the individual parameters revealed a significant effect of the growth mindset on brand trust: $\gamma=.36, p<.001$. The effect of a fixed mindset was not significant: $\gamma=-.11, p=.22$. Last, the effect of brand trust on purchase intention was significant: $\beta=.82$, $p<.001$. The indirect effect of a grow mindset on purchase intention through its influence on brand trust was significant: .29, p < .001 (see Figure 2 for a graphical representation of our full model). Conversely, the indirect effect of a fixed mindset was not significant: $-.09, \mathrm{p}=.22$. The squared multiple correlations for the endogenous variables were .10 for brand trust and .67 for purchase intention. 


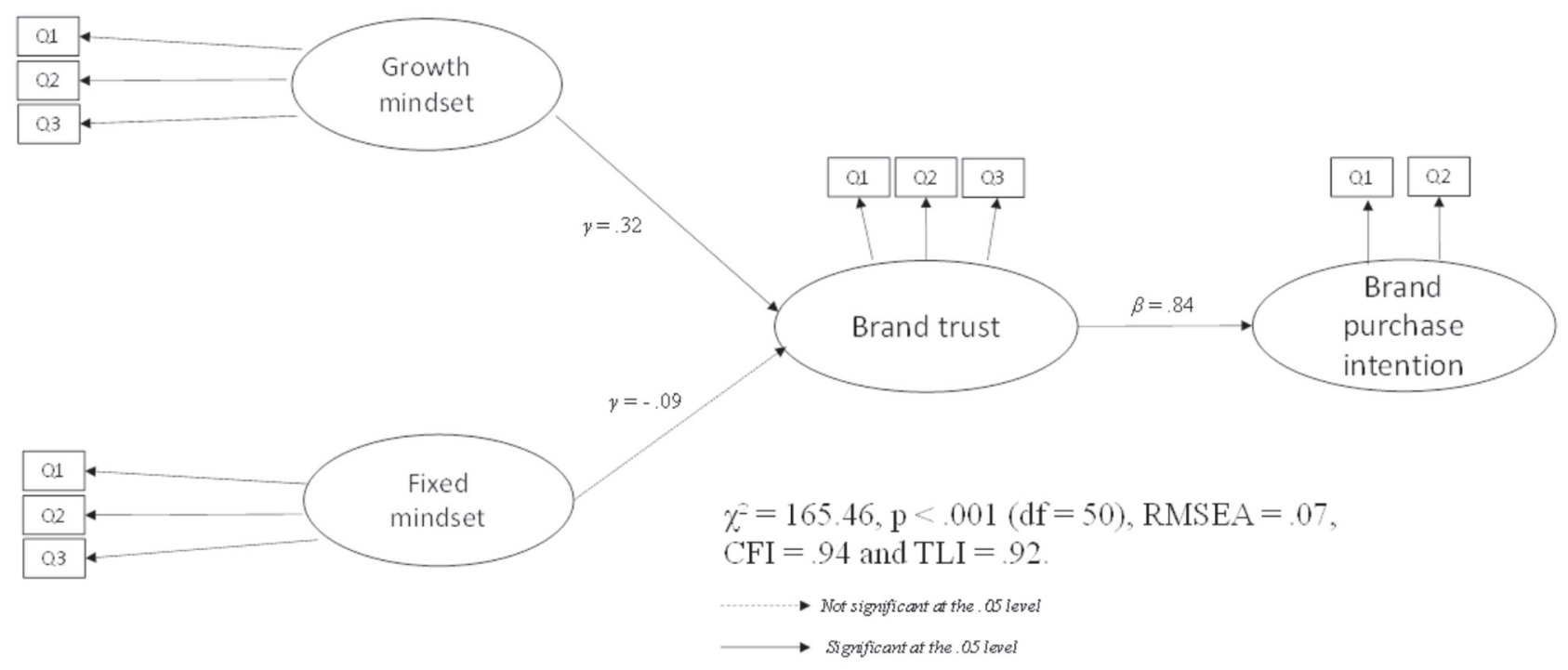

Figure 2. Summary of results of structural model

\section{Results of the latent class model}

We used the mixture modeling procedure on Mplus 7.1 to obtain our latent classes with all the items from the mindset questionnaire. To assess model fit, we followed the suggestions from Masyn (2013) in which several models are fit and the analyst uses a combination of statistical and "common sense" criteria to choose the best possible model. In addition, we used the 3-step approach to assess the influence of the latent classes on our dependent variables (Asparouhov \& Muthén, 2014), which has the advantage of taking into account the uncertainty in the classification procedure to estimate the coefficients and standard errors.

As shown in table 3, we started with a model with one latent class, followed by models with two, three, four, and five classes. From the results, we can see that after two classes, several indices of model fit did not show significant improvement. Hence, we might infer that the solution should involve around two to four classes. We used the bootstrap likelihood test in which a given model with $\mathrm{N}$ classes is tested against a model with $\mathrm{N}-1$ classes. The results showed that the model with three classes was better than the model with two classes: Log-likelihood = $-4259.99, \mathrm{df}=33, \mathrm{p}<.001$. We then conducted an analysis testing a model with four versus three classes. The results showed that the model with four classes appeared, on statistical grounds, to be better than the model with three classes: Loglikelihood $=-4181.18, \mathrm{df}=33, \mathrm{p}<.001$. From this, it was somewhat clear that our best solution involved between three and four classes. Both solutions had acceptable levels of entropy: .72 and .82 , respectively. The three-class solution had an adequate size of classes, ranging from 22 to $43 \%$. The four-class solution, however, had a class that was relatively small, at $7 \%$, which is not ideal. Hence, we used this indicator and more subjective criteria to reach the conclusion that a three-class solution represented a better alternative. 
Table 3

Summary of results of latent class models

\begin{tabular}{lcccccc}
\hline Model & Log-likelihood & Npar & Adj X & BIC & CAIC & Entropy \\
\hline 1 & -4360.767 & 32 & 12741.438 & 8915.125 & 8785.534 & \\
2 & -4259.991 & 65 & 13225.952 & 8913.215 & 8649.982 & 0.65 \\
3 & -4181.173 & 98 & 10977.948 & 8955.22 & 8558.346 & 0.72 \\
4 & -4123.346 & 131 & 10861.512 & 9039.207 & 8508.692 & 0.81 \\
5 & & & The best likelihood was not replicated & & \\
\hline
\end{tabular}

Examination of the three latent classes (see Figure 3) showed that latent class one (21\%) was characterized as having the lowest levels of growth and fixed mindsets (LGLF). Class two $(42 \%)$ was characterized as having the strongest growth mindset and medium levels of a fixed mindset (HGMF). Last, class three (36\%) had medium levels of a growth mindset combined with the highest levels of a fixed mindset (MGHF), as compared with the other two classes, yet the difference with class two was statistically significant but small in magnitude. Based on these results, we chose the three-class solution and hypothesized that the HGLF class two would show the highest brand trust and brand purchase intention as compared with the other two classes.

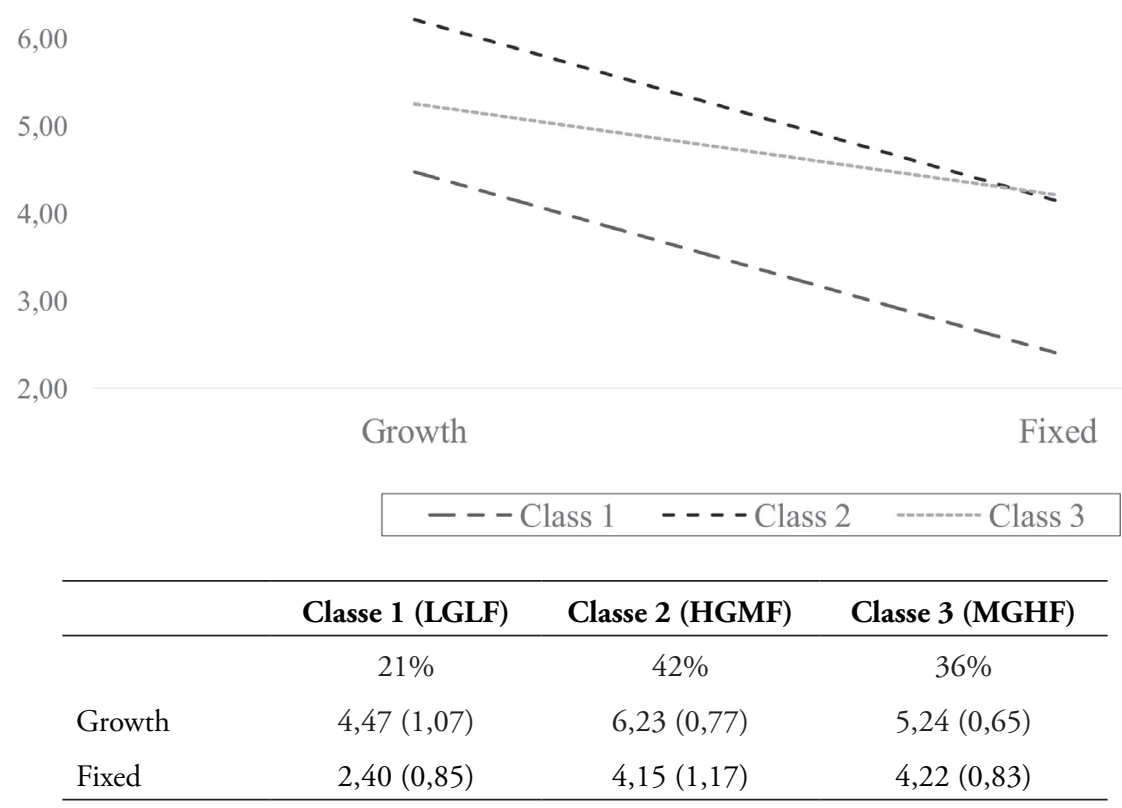

Figure 3. Latent classes

The results for brand trust showed a significant effect of class: $\chi^{2}=13.52, \mathrm{p}=.001$. Pairwise comparisons showed that the HGMF class $(\mathrm{M}=4.56$, S.E. $=.21)$ had significantly higher levels of brand trust than the LGLF class $(\mathrm{M}=$ 3.44, S.E. $=.30): \chi^{2}=9.03, \mathrm{p}=.003$. Similarly, the MGHF class $(M=4.85$, S.E. $=.23)$ had significantly higher levels than the LGLF class (M $=3.44$, S.E. $=.30): \chi^{2}=12.39, \mathrm{p}<.001$. Last, the HGMF and MGHF classes did not have reliable differences: $\chi^{2}=0.68, \mathrm{p}=.41$. 
The results for purchase intention showed a significant effect of class: $\chi^{2}=10.15, \mathrm{p}=.006$. Pairwise comparisons showed that the HGMF class $(M=5.24$, S.E. $=.25)$ had significantly higher levels of purchase intention than the LGLF class $(\mathrm{M}=3.83, \mathrm{~S} . \mathrm{E} .=.37): \chi^{2}=9.27, \mathrm{p}=.002$. Similarly, the MGHF class ( $M=5.14$, S.E. $=.29)$ had significantly higher levels than the LGLF class $(\mathrm{M}=3.83$, S.E. $=.37): \chi^{2}=6.93, \mathrm{p}=.008$. Last, the HGMF and MGHF classes did not have reliable differences: $\chi^{2}=0.06, \mathrm{p}=.81$.

\section{Brief discussion of study 2}

Under the latent variable conceptualization, our results showed that a growth mindset was positively related to brand trust, thus supporting hypothesis one. We did not find a significant relationship between a fixed mindset and brand trust, hence failing to support hypothesis two. Our results were somewhat consistent with a previous investigation in which the role of mindsets in brand evaluations was established (Yin et al., 2016). Similarly, our results under the latent class conceptualization showed that the HGMF class had higher levels of brand trust than the LGLF class, thus partially supporting hypothesis three. In addition, brand trust had a positive relationship with purchase intention. Similarly, the indirect influence of a growth mindset on purchase intention, through its influence on brand trust, was also significant, hence supporting hypothesis four. Last, the HGMF class had higher levels of purchase intention than the LGLF class, thus partially supporting hypothesis five. Hence, our results showed promising, yet somewhat preliminary support for the role of mindsets in consumers' reactions to a negative event involving a corporate brand.

\section{General discussion}

The purpose of our investigation was twofold. First, we conducted a qualitative study using personal interviews to understand if consumers used the stability versus malleability component in their discourse to either explain the decision to trust or buy a Mexican brand in the future that had been involved in a negative event. Second in study 2 we examined the influence of mindsets on the consumers' reactions to the same negative event under two conceptualizations of implicit theories. For the most part, both studies supported our predictions. We now discuss our results with the goal of integrating the findings from the qualitative and quantitative approaches (Johnson \& Onwuegbuzie, 2004).

\section{I Stability versus malleability}

At the core of implicit theories is belief about the stability or malleability of things. This simple, yet powerful dimension has been used to assess beliefs about the nature of intelligence (Dweck, 2000), creativity (Karwowski, 2014), personality (Dweck, 2008), organizational behavior (Murphy \& Dweck, 2010), and, recently, consumer behavior (Murphy \& Dweck, 2016). Our results showed that belief about the malleability of corporate brands, thus holding a growth mindset, helped consumers express their willingness to trust the brand involved in the incident. This finding was consistent with previous investigations (Yin et al., 2016), involving different conceptualizations of mindsets and different research approaches. Specifically, a growth mindset had a positive influence on brand trust. Latent classes characterized by high levels of a growth mindset showed more willingness to trust the brand, and during their natural discourse, the consumers explained that all companies made mistakes but were capable of improving their practices with time, thus indirectly implying a growth mindset.

Conversely, a belief in the stability of things, i.e. a fixed mindset, led to inconclusive results. Specifically, a fixed mindset did not have a significant influence on brand trust. Similarly, classes with higher levels of a fixed mindset did not show lower brand trust (it looks like a growth mindset is more important), yet in their natural discourse, some consumers mentioned their belief 
in stability as a way to justify their decision not to trust the brand. Overall, our quantitative results were not consistent with previous studies (Yin et al., 2016). Yet, our qualitative results appeared to indicate that belief in the stability of things played a role in explaining consumers' unwillingness to trust a brand after a negative event.

Regarding the positive consequences of brand trust, our results showed that this was positively related to purchase intention. Similarly, classes with high growth mindsets were more willing to buy the brand again. Our qualitative results also suggested that trust was relevant to understand willingness but also unwillingness to buy the products of a corporate brand. These results were consistent with the proposition that brand trust plays an important role in the consumer decision-making process (Xie et al., 2015).

\subsection{Implications}

We see two potential implications of our investigation. First, our results showed that implicit theories or mindsets played an important role in understanding consumers' reactions after negative events. Hence, to understand product failures and product harm crises, consumer behavior scholars should pay close attention not only to brand characteristics but also to consumers' beliefs about the stability and malleability of brands. In addition, it would also be helpful to understand how malleable consumers' beliefs are. Research shows that companies are able to shape consumers' beliefs about the stability or malleability of their brands (Murphy \& Dweck, 2016). Specifically, some brands might position themselves as classic and stable whereas others might position themselves as innovative and constantly growing. Differences in how brands decide to position themselves within the stability versus malleability dimension could have important implications for brand trust after negative events and for the launching of new products or drastic product changes (Yorkston et al., 2010). Hence, brand managers would do well to pay close attention to consumers' mindsets and to how their brands are positioned within the stability versus malleability dimension, given that they could have important implications.

A second related implication of our investigation concerns the analytical and methodological approaches chosen. First, as mentioned in our introduction, consumer scholars should avoid dichotomizing variables to form groups, as are often used in mindset research (Yin et al., 2016). There are more robust and reliable techniques such as latent class and latent profile analysis to form groups. Second, we truly believe that our mixed method research approach provided a more complete understanding of how mindsets influence trust and purchase intention. From our quantitative results, it was clear that a growth mindset played an important role. This finding received additional support from our personal interviews. Yet, regarding a fixed mindset, the conclusions from our quantitative results did not match those from our qualitative findings. Specifically, the consumers seemed to use the stability dimension to justify their decisions not to trust or buy the brand involved in the incident. Yet, our quantitative results did not support this conclusion. One possible explanation for the observed mismatch might be that our fixed mindset items were not highly endorsed, limiting the range of responses. The observed means for a growth mindset were higher than the ones for a fixed mindset.

\subsection{Limitations and future directions}

Our investigation had several limitations. First, in study 2 we used a sample of college students, which limits our ability to generalize our results. Future studies might want to conduct similar investigations with more representative samples of the population. Our second limitation was that even though we found support for the stability versus malleability dimension in both studies, it was also evident that other factors were likely to influence consumers' responses after a negative event. Specifically, our qualitative study 
showed that factors such as the current equity of the brand involved (Yin et al., 2016) and the additional perceived brand qualities, good prices, and good products, played an important role as well. Hence, future research could measure these additional factors and examine the extent to which mindsets are able to explain brand trust beyond the contribution of other important factors. Another limitation is that we decided to create a new measure assessing the stability and malleability of corporate brands. While the results from the validation analysis and the actual test of the hypotheses appeared to indicate that the new measure had acceptable psychometric properties, it was also clear that there were areas for improvement, which might explain why we did not find a significant influence of a fixed mindset on brand trust or purchase intention. Hence, we could conclude that our measure of stability and malleability of corporate brands is still at the stage of development and refinement.

In sum, in two studies we found strong support for the role of a growth mindset in brand trust and purchase intention after a known brand had been involved in a negative event. The role of a fixed mindset was not as clear as we had hoped. Yet, we still believe that the examination of mindsets holds a promising future for understanding different aspects of consumer behavior.

\section{Note}

1 A pilot study with 103 participants showed no differences in brand trust between participants who knew about the incident versus participants who did not know $(\mathrm{F}=1.95$, $\mathrm{p}=.17, \mathrm{Mknew}=5.32, \mathrm{SD}=2.68$ versus Mdidnot $=6.17$, $\mathrm{SD}=2.85$ ) before participating in our investigation

\section{References}

Aaker, D. A. (1991). Managing brand equity: Capitalizing on the value of a brand name. New York, NY.: The Free Press.

Aaker, J. L., Fournier, S., \& Brasel, S. A. (2004). When good brands do bad. Journal of Consumer research, 31(1), 1-16.
Alvarez, C., \& Fournier, S. (2016). Consumers' relationships with brands. Current Opinion in Psychology, 10, 129-135.

Asparouhov, T. \& Muthén, B. (2014). Auxiliary variables in mixture modeling: 3-step approaches using Mplus. Webnote 15, pp. 1-51. Retrieved from https://www.statmodel.com/download/ webnotes/webnote15.pdf

Bergman, L. R., \& Andersson, H. (2010). The person and the variable in developmental psychology", Journal of Psychology, 218, 155-165.

Braun, V., \& Clarke, V. (2006). Using thematic analysis in psychology. Qualitative research in psychology, 3(2), 77-101

Brexendorf, T. O., \& Keller, K. L. (2017). Leveraging the corporate brand: The importance of corporate brand innovativeness and brand architecture. European Journal of Marketing, 51(9/10), 1530-1551.

Brown, T. A. (2006). Confirmatory factor analysis for applied research. New York, NY: Guilford Press.

Calvo Porral, C., \& Levy-Mangin, J. P. (2016). Food private label brands: the role of consumer trust on loyalty and purchase intention. British Food Journal, 118(3), 679-696.

Chaudhuri, A., \& Holbrook, M. B. (2001). The chain of effects from brand trust and brand affect to brand performance: the role of brand loyalty. Journal of marketing, 65(2), 81-93.

Cleeren, K., Dekimpe, M. G., \& van Heerde, H. J. Marketing research on product-harm crises: a review, managerial implications, and an agenda for future research. Journal of the Academy of Marketing Science, 45 (5), 593-615. doi.org/10.1007/s1174

Dawar, N., \& Pillutla, M. M. (2000). Impact of product-harm crises on brand equity: The moderating role of consumer expectations. Journal of marketing research, 37(2), 215-226. 
De Jonge, J., Van Trijp, H., Renes, R. J., \& Frewer, L. J. (2010). Consumer confidence in the safety of food and newspaper coverage of food safety issues: A longitudinal perspective. Risk analysis, 30(1), 125-142.

Doney, P. M., \& Cannon, J. P. (1997). An examination of the nature of trust in buyer-seller relationships. Journal of Marketing, 61, 35-51

Dweck, C. S. (2000). Self-theories: Their role in motivation, personality, and development. New York, NY: Psychology Press.

Dweck, C. S. (2008). Can personality be changed? The role of beliefs in personality and change. Current directions in psychological science, 17(6), 391-394.

Han, S. H., Nguyen, B., \& Lee, T. J. (2015). Consumer-based chain restaurant brand equity, brand reputation, and brand trust. International Journal of Hospitality Management, 50, 84-93.

Johnson, R. B., \& Onwuegbuzie, A. J. (2004). Mixed methods research: A research paradigm whose time has come. Educational researcher, 33(7), 14-26.

Karwowski, M. (2014). Creative mindsets: Measurement, correlates, consequences. Psychology of Aesthetics, Creativity, and the Arts, 8(1), 62-70.

Lassoued, R., \& Hobbs, J. E. (2015). Consumer confidence in credence attributes: The role of brand trust. Food Policy, 52, 99-107.

Levy, S. R., Stroessner, S. J., \& Dweck, C. S. (1998). Stereotype formation and endorsement: The role of implicit theories. Journal of Personality and Social Psychology, 74(6), 1421-1436.

Masyn, K. (2013). Latent class analysis and finite mixture modeling. In L.D. Little. (Ed.) The Oxford handbook of quantitative methods in psychology. (pp. 551-611). New York, NY: Oxford University Press.
Morgan, R. M., \& Hunt, S. D. (1994). The commitment-trust theory of relationship marketing. The journal of marketing, 58, 20-38.

Murphy, M. C., \& Dweck, C. S. (2010). A culture of genius: How an organization's lay theory shapes people's cognition, affect, and behavior. Personality and Social Psychology Bulletin, 36(3), 283-296.

Murphy, M. C., \& Dweck, C. S. (2016). Mindsets shape consumer behavior. Journal of Consumer Psychology, 26(1), 127-136.

Neel, R., \& Lassetter, B. (2015). Growing fixed with age: Lay theories of malleability are target-age specific. Personality and Social Psychology Bulletin, 41 (11), 1505-1522. doi. org/10.1177/0146167215600529

Onwuegbuzie, A. J., \& Teddlie, C. (2003). A framework for analyzing data in mixed methods research. In A. Tashakkori \& C. Teddlie (Eds.). Handbook of mixed methods in social and behavioral research. (pp. 351-383). Thousand Oaks, CA: Sage.

Plaks, J. E. (2017). Implicit theories: Assumptions that shape social and moral cognition. Advances in Experimental Social Psychology, 56, 259-310.

Puzakova, M., Kwak, H., \& Rocereto, J. F. (2013). When humanizing brands goes wrong: The detrimental effect of brand anthropomorphization amid product wrongdoings. Journal of Marketing, 77 (3), 81-100. doi.org/10.1509/jm.11.0510

Schumann, K., Zaki, J., \& Dweck, C. (2014). Addressing empathy deficit: Beliefs about the malleability of empathy predict effortful responses when empathy is challenging. Journal of Personality and Social Psychology, 107 (3), 474-493.

Tullett, A., \& Plaks, J. E. (2016). Testing the link between empathy and lay theories of happiness. Personality and Social Psychology Bulletin, 42 (11), 1505-1521. 
Tybout, A. M., \& Calkins, T. (2005). (Eds.). Kellogg on branding. Hoboken, NJ: Wiley.

West, S. G., Taylor, A. B., \& Wu, W. (2012). Model fit and model selection in structural equation modeling. In R.H. Hoyle. (Ed.). Handbook of structural equation modeling, (pp. 209-231). New York, NY.: Guilford Press.

Wheeler, S. C., \& Omair, A. (2016). Potential growth areas for implicit theories research. Journal of consumer psychology, 26(1), 137-141

Xie, Y., Batra, R., \& Peng, S. (2015). An extended model of preference formation between global and local brands: The roles of identity expressiveness, trust, and affect. Journal of International Marketing, 23(1), 50-71.
Yannopoulou, N., Koronis, E., \& Elliott, R. (2011). Media amplification of a brand crisis and its affect on brand trust. Journal of Marketing Management, 27(5-6), 530-546.

Yin, C. Y., Yu, H. Y., \& Poon, P. (2016). Consumers' attributions and brand evaluations in product-harm crises: The role of implicit theories of personality. Journal of Consumer Behaviour, 15(1), 87-95.

Yorkston, E. A., Nunes, J. C., \& Matta, S. (2010). The malleable brand: The role of implicit theories in evaluating brand extensions. Journal of Marketing, 74(1), 80-93. 


\section{Appendix A}

Picture uploaded to social media and used in both studies

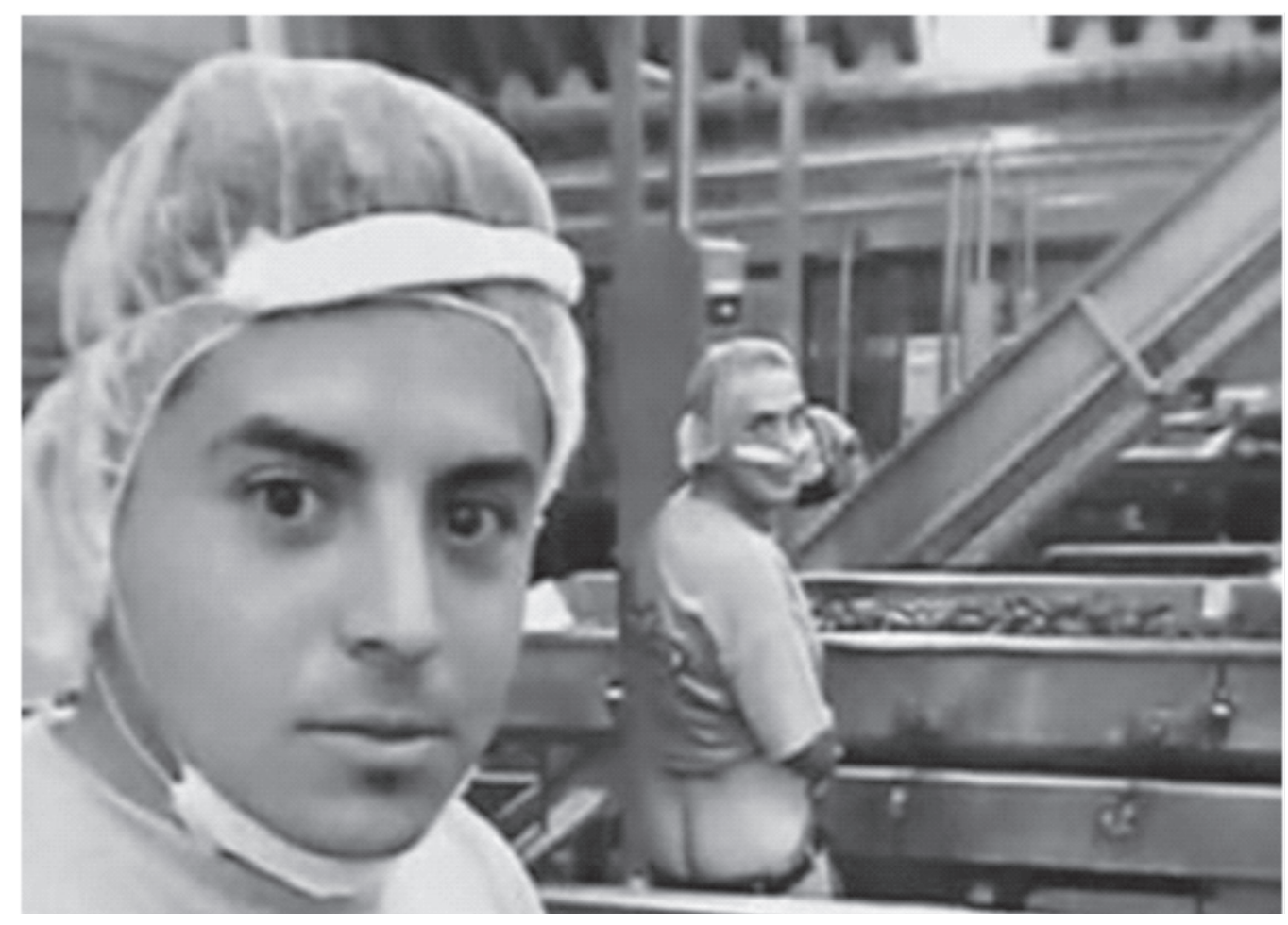


About the Authors:

1. Rogelio Puente-Díaz, PhD., Universidad Anáhuac, Estado de México, México.

E-mail:rogelio.puente@anahuac.mx]

ORCID

iD 0000-0001-6777-7103

2. Judith Cavazos-Arroyo, PhD., Universidad Popular Autónoma del Estado de Puebla, Puebla, México. E-mail:judith.cavazos@upaep.mx

ORCID

iD $0000-0002-6258-289 \mathrm{X}$

\section{Contribution of each author}

\begin{tabular}{lcc}
\hline Contribution & Rogelio Puente-Díaz & Judith Cavazos-Arroyo \\
\hline 1. Definition of research problem & $\sqrt{ }$ \\
2. Development of hypotheses or research questions (empirical studies) & $\sqrt{ }$ \\
3. Development of theoretical propositions (theoretical work) & $\sqrt{ }$ \\
4. Theoretical foundation/Literature review & \\
5. Definition of methodological procedures & $\sqrt{ }$ \\
6. Data collection & \\
7. Statistical analysis & \\
8. Analysis and interpretation of data & $\sqrt{ }$ \\
9. Critical revision of the manuscript & $\sqrt{ }$ \\
10. Manuscript writing & \\
11. Other (please specify which) & \\
\hline
\end{tabular}

